\title{
北祁连山西段志留纪高硅埃达克岩: 洋壳减压熔融的证据
}

\author{
陈育晓，夏小洪，宋述光* \\ 北京大学地球与空间科学学院, 北京大学造山带与地壳演化教育部重点实验室, 北京 100871 \\ * 联系人, E-mail: sgsong @pku.edu.cn
}

国家重点基础研究发展计划(2009CB825007)、国家自然科学基金(40825007, 40821002)和中国地质调查局地质调查工作项目(1212011121258)资助

\begin{abstract}
摘要 北祁连山西段謷油沟地区奥长花岗岩具有与高硅埃达克岩相似的地球化学特征: 高 $\mathrm{SiO}_{2}$, 富 $\mathrm{Na}_{2} \mathrm{O}$ (高 $\left.\mathrm{Na} / \mathrm{K}\right)$, 高 $\mathrm{Sr} / \mathrm{Y}$, 高 $(\mathrm{La} / \mathrm{Yb})_{\mathrm{N}}, \mathrm{Sr}$ 正异常, 相对富集大离子亲石元素(LILE)和轻 稀土(LREE), 亏损 $\mathrm{Nb}, \mathrm{Ta}$ 和 Ti. 锆石 SHRIMP 定年结果为 $438 \pm 3 \mathrm{Ma}$, 表明其形成与北祁连古 洋壳的俯冲有关，但其形成时间明显晚于北祁连山榴辉岩的变质时间(460 490 Ma). Sr-Nd 同 位素结果显示其 $I_{\mathrm{Sr}}$ 和 $\varepsilon_{\mathrm{Nd}}(t)$ 值分别为 0.7044 0.7047 和 +3.0 +4.1, 暗示其来源于新生的洋壳 物质. 结合北衩连造山带的构造演化背景, 謷油沟奥长花岗岩可能是俯冲板片变质成榴辉岩 后，在折返过程中发生近等温或升温减压熔融，在大约 $60 \mathrm{~km}$ 深度熔融形成.
\end{abstract}

\section{关键词}

高硅埃达克岩

早志留纪

榴辉岩

折返熔融

北祁连山西段
埃达克岩是指具有特定地球化学性质(高 $\mathrm{Sr}$ 低 $\mathrm{Y}$, 高 $\mathrm{Sr} / \mathrm{Y}$ 和 $\left.(\mathrm{La} / \mathrm{Yb})_{\mathrm{N}}\right)$ 的中酸性火成岩 ${ }^{[1]}$. 埃达克岩 的成因问题一直是学术界探讨的热点之一, 因为这 不仅对古大洋及古板块构造格局演化的恢复具有重 要意义 ${ }^{[1 ~ 6]}$, 而且可能具有与构成大陆地壳主要部分 的太古代英云闪长岩-奥长花岗岩-花岗闪长岩(TTG) 系列岩石相关的成因机制 ${ }^{[7 ~ 12]}$.

最初认为, 埃达克岩的形成与热的年轻的俯冲 板片熔融有着密切的联系, 主要分布在环太平洋地 $区^{[7,8,13,14]}$. 但是, 新的研究结果表明, 加厚下地壳或 拆沉下地壳及玄武质母岩浆的高压结晶分异等成因 模式, 也可能是埃达克岩的形成机制 ${ }^{[15 \sim 25]}$. 这些新 模式的提出暗示了埃达克岩成因的多样性. 而俯冲 板片成因模式具有一定的局限性, 如高的地热梯度, 相对热的年轻板片, 平缓俯冲和板片窗等较为苛刻 的熔融条件 ${ }^{[1,6,7,26]}$. “热”的来源虽然是岩浆产生的重 要条件, 但是并非熔融的唯一条件 ${ }^{[27]}$. 减压熔融已 经被证实是部分熔融的重要机制之一, 如造山带中
变质岩在折返直至出露地表过程中由于快速抬升, 压力迅速降低, 含水矿物发生分解脱水, 引起周围岩 石固相线降低而发生熔融, 结果导致熔体的形 成 ${ }^{[28 ~ 32]}$. 如果高压/超高压岩石在减压过程中没有显 著的脱水作用，地壳岩石是不可能发生熔融的.

本文报道了北祁连造山带西段謷油沟地区早志 留纪高硅埃达克岩的地球化学、 Sr-Nd 同位素特征及 年代学证据, 结合北祁连造山带的构造演化历史及 其与区内榴辉岩形成的时间关系, 我们提出了区内 埃达克岩可能是榴辉岩折返过程中发生熔融的结果. 这一新模式的提出对埃达克岩成因模式的进一步探 讨和北祁连早古生代板块构造演化作用研究具有重 要的意义.

\section{1 地质概况}

祁连造山带位于青藏高原北部, 是一个早古生 代大洋俯冲带 ${ }^{[33]}$. 该俯冲带沿北西-南东向展布，西 端被左行走滑的阿尔金断裂所切. 其北部为阿拉善

英文版见: Chen Y X, Xia X H, Song S G. Petrogenesis of Aoyougou high-silica adakite in the North Qilian orogen, NW China: Evidence for decompression melting of oceanic slab. Chin Sci Bull, 2012, 57, doi: 10.1007/s11434-012-5069-3 
地块, 南部为柴达木地块. 带内发育有早古生代的蛇 绿混杂岩、不同变质级别的高压变质岩、岛弧火山岩 和花岗岩侵人体、志留纪复理石建造、泥盆纪磨拉石
建造和石炭纪-三叠纪的沉积盖层 ${ }^{[34,35]}$ (图 1(a)).

謷油沟位于北祁连山西段, 甘肃省肃南县祁青 乡东南方向约 $8 \mathrm{~km}$, 出露有著名的、由蛇纹石化橄榄
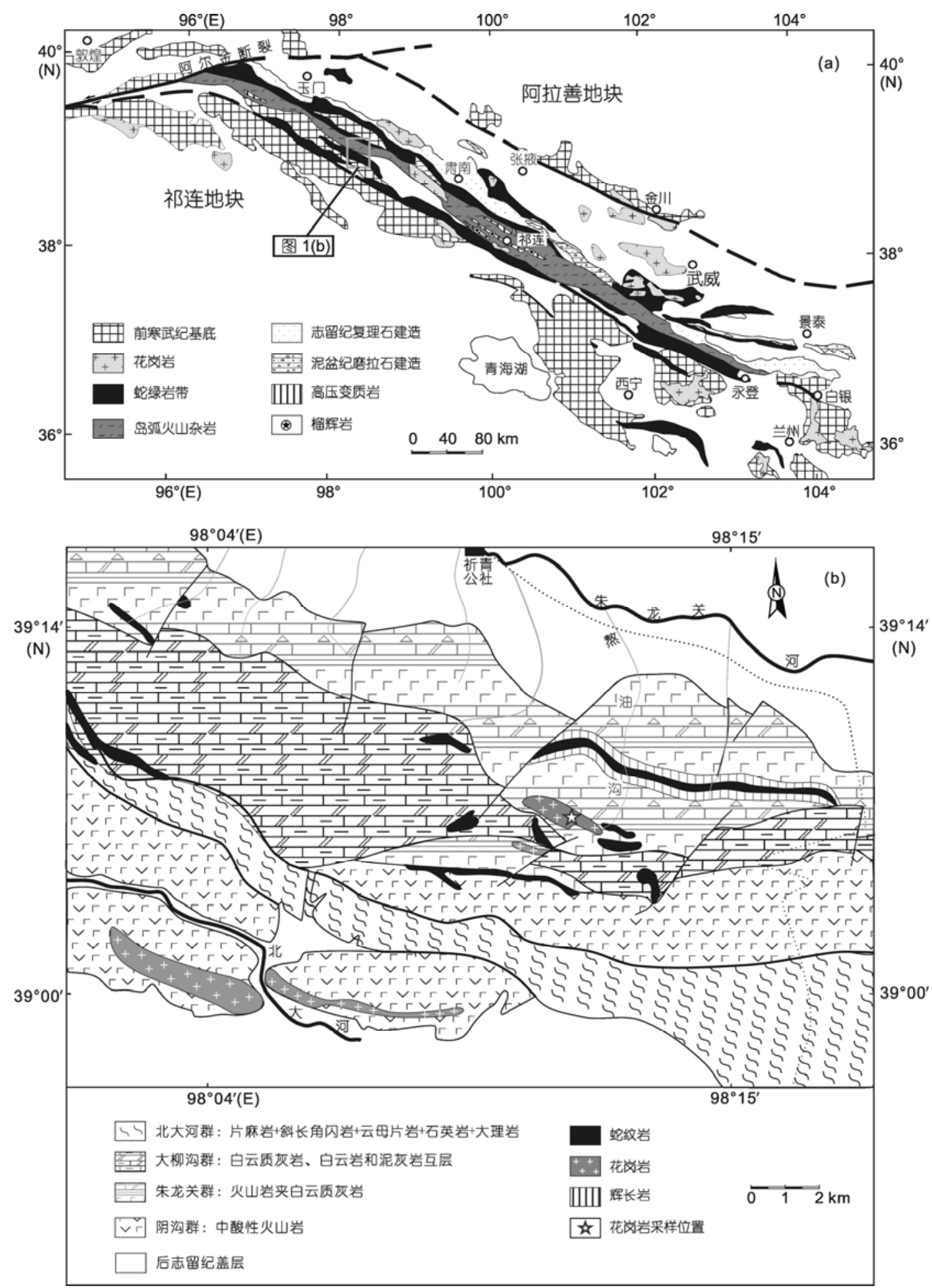

图 1 北祁连造山带地质简图(a) ${ }^{[36]}$ 及鰲油沟地区地质图(b) (据祁连山幅 1:20 万地质图修改) 
岩、辉长岩和基性火山岩组成的獒油沟蛇绿岩 ${ }^{[37]}$, 其 中辉长岩锆石的 $\mathrm{U}-\mathrm{Pb}$ 年龄为 $504 \pm 6 \mathrm{Ma}{ }^{[38]}$. 本文所 研究的花岗岩体位于蛇绿岩南部, 其出露面积小于 $1 \mathrm{~km}^{2}$, 近南东向展布(图 1(b)), 以岩枝或岩脉状侵人 朱龙关群基性火山岩中(图 2(a)), 岩体与围岩的接触 边界上发育有明显的烘烤现象(图 2(b)).

\section{2 岩石学特征}

本文样品具典型的中粗粒花岗结构(图 2(c)), 主 要矿物有斜长石 (自形, $60 \%$ 70\%), 石英(>20\%), 钾 长石 $(<5 \%)$, 暗色矿物(几乎完全绿泥石化, $<5 \%$ ), 副 矿物为磷灰石、锆石、榍石等. 斜长石发生弱的钠帘 石化和绢云母化, 且发育岩浆结晶的震荡环带(图 2(d)), 其成分以更长石为主, 从中间到边缘, An 值从 33.56 逐渐降到 10.75 (表 1), 反映了岩浆结晶分异的 过程.

\section{3 锆石 U-Pb 同位素年代学特征}

本文选取样品 09AY-14 进行锆石的 U-Pb 定年 分析，锆石分选在河北省廊坊市区域地质调查研究 院进行，具体步骤如下：首先将岩石样品研磨至大约 100 目，接着采用标准的重液、磁选和双目显微镜分 选技术, 从约 $0.5 \mathrm{~kg}$ 花岗岩样品中分选出了约 200 颗锆石, 然后将选出的锆石颗粒和数粒锆石标样 TEMORA 置于环氧树脂中, 磨至约一半, 并抛光镀 金. 锆石的阴极发光照相 $(\mathrm{CL})$ 是在北京大学物理学 院 FEI PHILIPS XL 30 型扫描电子显微镜室进行, 实 验条件为 $15 \mathrm{kV}, 120 \mu \mathrm{A}$. 锆石 U-Pb 年龄分析在北 京离子探针中心的 SHRIMP II 上完成. 本次测试采用 标准锆石 $\mathrm{TEMORA}\left({ }^{206} \mathrm{~Pb} /{ }^{238} \mathrm{U}\right.$ 参考年龄: $\left.417 \mathrm{Ma}\right)$ 进行同位素分馏校正, 利用标准锆石 $\mathrm{M} 257\left({ }^{206} \mathrm{~Pb} /{ }^{238} \mathrm{U}\right.$ 参考年龄: $572 \mathrm{Ma}, \mathrm{U}$ 含量为 $238 \mu \mathrm{g} \mathrm{g}^{-1}$ ) 标定所测锆 石的 $\mathrm{U}, \mathrm{Th}$ 和 $\mathrm{Pb}$ 的含量. 为保证数据质量, 每测 3 个
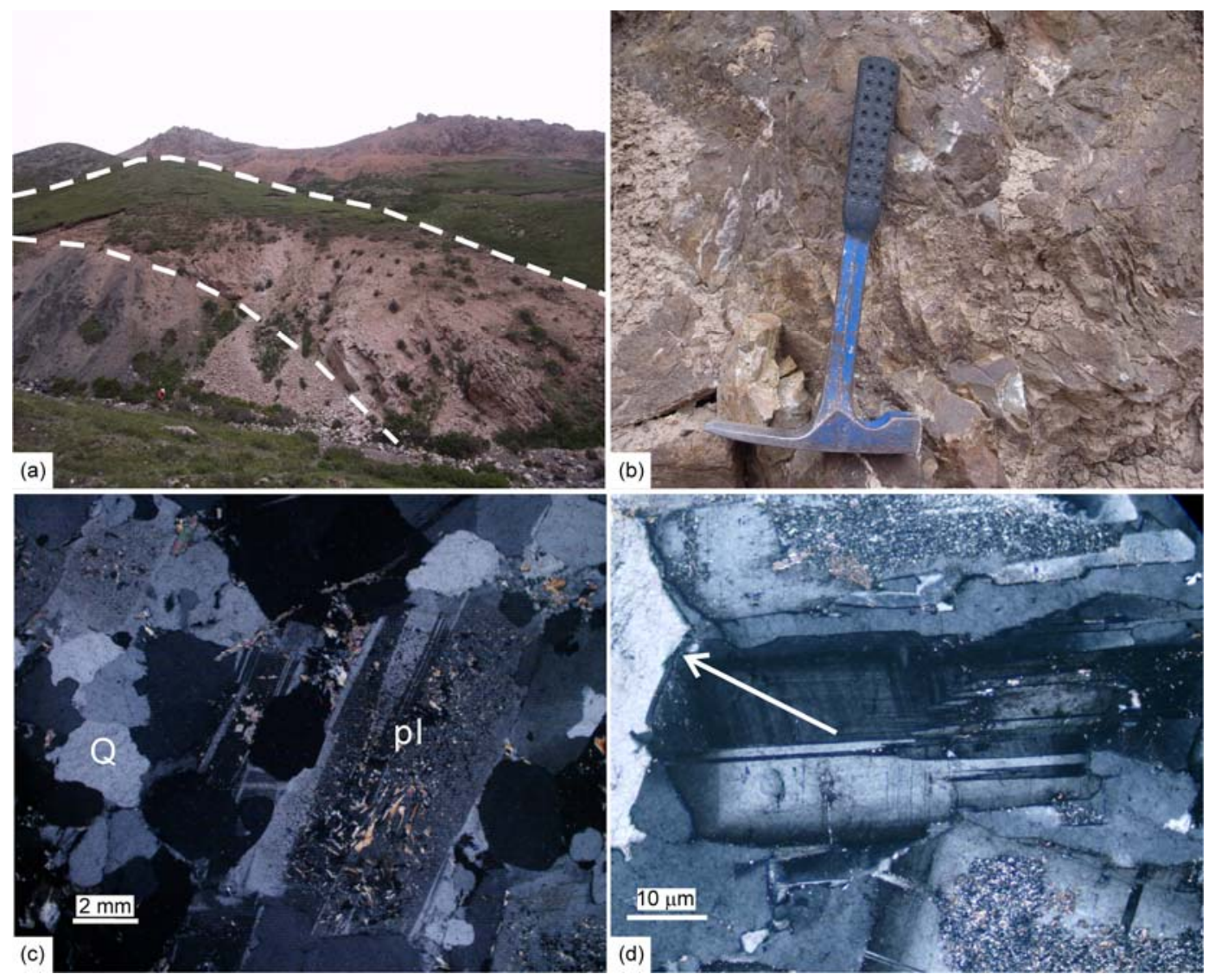

图 2 謷油沟花岗岩野外 $((\mathbf{a}),(\mathbf{b}))$ 及显微结构 $((\mathbf{c}),(\mathbf{d}))$ 照片

（a）虚线中间为奥长花岗岩露头，侵人到朱龙关群基性火山岩中; (b) 接触边上发育明显的烘烤边和冷凝边; (c) 中粗粒花岗岩结构 (10QL-16); (d) 斜长石的岩浆结晶环带 (10QL-18) 
表 1 奥长花岗岩(10QL-18) 中斜长石从核部(3.1)到边部 (3.13)的电子探针成分 $(w t \%)$

\begin{tabular}{|c|c|c|c|c|c|c|c|c|c|c|c|c|c|}
\hline 点号 & 3.1 & 3.2 & 3.3 & 3.4 & 3.5 & 3.6 & 3.7 & 3.8 & 3.9 & 3.10 & 3.11 & 3.12 & 3.13 \\
\hline $\mathrm{SiO}_{2}$ & 59.36 & 59.39 & 59.88 & 59.72 & 59.99 & 59.53 & 60.02 & 59.64 & 61.23 & 61.98 & 61.97 & 63.78 & 65.76 \\
\hline $\mathrm{TiO}_{2}$ & 0.00 & 0.04 & 0.02 & 0.01 & 0.00 & 0.04 & 0.00 & 0.04 & 0.00 & 0.04 & 0.00 & 0.03 & 0.00 \\
\hline $\mathrm{Al}_{2} \mathrm{O}_{3}$ & 24.82 & 25.51 & 25.69 & 25.81 & 25.70 & 26.21 & 25.52 & 25.58 & 24.81 & 24.27 & 23.90 & 22.67 & 21.87 \\
\hline $\mathrm{Cr}_{2} \mathrm{O}_{3}$ & 0.00 & 0.00 & 0.00 & 0.03 & 0.02 & 0.00 & 0.02 & 0.00 & 0.00 & 0.02 & 0.00 & 0.08 & 0.00 \\
\hline $\mathrm{FeO}$ & 0.22 & 0.11 & 0.15 & 0.13 & 0.18 & 0.19 & 0.17 & 0.13 & 0.04 & 0.08 & 0.13 & 0.10 & 0.02 \\
\hline $\mathrm{MnO}$ & 0.03 & 0.00 & 0.00 & 0.00 & 0.00 & 0.06 & 0.02 & 0.00 & 0.03 & 0.00 & 0.04 & 0.02 & 0.01 \\
\hline $\mathrm{MgO}$ & 0.01 & 0.02 & 0.00 & 0.03 & 0.00 & 0.05 & 0.01 & 0.03 & 0.02 & 0.01 & 0.00 & 0.00 & 0.00 \\
\hline $\mathrm{CaO}$ & 6.40 & 7.19 & 7.06 & 6.90 & 6.88 & 7.10 & 6.62 & 6.90 & 5.89 & 5.58 & 4.81 & 3.88 & 2.28 \\
\hline $\mathrm{Na}_{2} \mathrm{O}$ & 8.03 & 7.76 & 8.01 & 7.77 & 7.94 & 7.58 & 8.14 & 8.26 & 8.30 & 8.49 & 8.96 & 9.49 & 10.34 \\
\hline $\mathrm{K}_{2} \mathrm{O}$ & 0.25 & 0.14 & 0.17 & 0.18 & 0.18 & 0.13 & 0.12 & 0.16 & 0.18 & 0.18 & 0.25 & 0.35 & 0.19 \\
\hline $\mathrm{NiO}$ & 0.00 & 0.09 & 0.00 & 0.00 & 0.00 & 0.02 & 0.05 & 0.01 & 0.04 & 0.05 & 0.00 & 0.00 & 0.00 \\
\hline 总量 & 99.12 & 100.25 & 100.98 & 100.58 & 100.90 & 100.91 & 100.68 & 100.75 & 100.55 & 100.69 & 100.06 & 100.39 & 100.47 \\
\hline An & 30.18 & 33.56 & 32.46 & 32.60 & 32.06 & 33.84 & 30.75 & 31.30 & 27.87 & 26.40 & 22.61 & 18.05 & 10.75 \\
\hline $\mathrm{Ab}$ & 68.46 & 65.66 & 66.57 & 66.40 & 66.96 & 65.46 & 68.56 & 67.84 & 71.13 & 72.60 & 76.01 & 79.98 & 88.14 \\
\hline Or & 1.37 & 0.78 & 0.97 & 0.99 & 0.98 & 0.70 & 0.69 & 0.86 & 1.00 & 1.00 & 1.38 & 1.97 & 1.11 \\
\hline
\end{tabular}

样品点, 测 1 次锆石标样. 普通铅根据实测 ${ }^{204} \mathrm{~Pb}$ 校 正. 数据处理采用 Ludwig SQUID1.0 及 ISOPLOT ${ }^{[39]}$ 程序, 详细的分析流程及原理参考文献[40,41]. 表 2 所列单个数据点的误差均为 $1 \sigma$, 样品采用加权平均 年龄, 其置信度为 $2 \sigma$, 置信水平为 $95 \%$, 详细的测试 结果见表 2.

锆石颗粒大小较均匀, 自形程度较高, 为半自形 到自形的长柱状, 长约 50 120 $\mu \mathrm{m}$, 宽约 $20 \sim 40 \mu \mathrm{m}$.
锆石表面干净, 包裹体较少, CL 图像显示大多数锆 石内部发育清晰的岩浆震荡环带(图 3), 且结构均一, 无残核. 分析结果显示 (表 2) 锆石的 U 和 Th 含量 均较低 (U: 99 162 $\mu \mathrm{g} \mathrm{g}^{-1}$, Th: 46 97 $\mu \mathrm{g} \mathrm{g}^{-1}$ ), Th/ $\mathrm{U}$ 比值为 $0.46 \sim 0.65 .13$ 个测试点的 ${ }^{206} \mathrm{~Pb} /{ }^{238} \mathrm{U}$ 年龄值分 布于 431 444 Ma 之间, 加权平均年龄为 $438 \pm 3 \mathrm{Ma}$ (95\%的置信度, MSWD=0.46)（图 4), 代表謷油沟奥 长花岗岩的结晶年龄.

表 2 謷油沟奥长花岗岩(09AY-14)锆石 SHRIMP U-Th-Pb 分析数据

\begin{tabular}{|c|c|c|c|c|c|c|c|c|c|c|c|}
\hline 测点 & $\begin{array}{c}\mathrm{U} \\
\left(\mu \mathrm{g} \mathrm{g}^{-1}\right)\end{array}$ & $\begin{array}{c}\text { Th } \\
\left(\mu \mathrm{g} \mathrm{g}^{-1}\right)\end{array}$ & $\mathrm{Th} / \mathrm{U}$ & $\begin{array}{c}{ }^{206} \mathrm{~Pb}^{*} \\
\left(\mu \mathrm{g} \mathrm{g}^{-1}\right)\end{array}$ & ${ }^{206} \mathrm{~Pb}_{\mathrm{C}} / \%$ & ${ }^{207} \mathrm{~Pb}^{*} /{ }^{235} \mathrm{U}$ & $\pm \%$ & ${ }^{206} \mathrm{~Pb}^{*} /{ }^{238} \mathrm{U}$ & $\pm \%$ & $\begin{array}{l}{ }^{206} \mathrm{~Pb} /{ }^{238} \mathrm{U} \\
\text { 年龄 }(\mathrm{Ma})\end{array}$ & $\pm 1 \sigma$ \\
\hline 1 & 104 & 51 & 0.51 & 6.15 & 0.00 & 0.5202 & 3.4 & 0.0691 & 1.4 & 431.0 & 6.0 \\
\hline 2 & 104 & 53 & 0.52 & 6.23 & 0.00 & 0.5380 & 3.4 & 0.0695 & 1.4 & 433.1 & 6.0 \\
\hline 3 & 99 & 46 & 0.48 & 5.98 & 0.19 & 0.5291 & 4.1 & 0.0700 & 1.5 & 436.4 & 6.3 \\
\hline 4 & 122 & 60 & 0.51 & 7.42 & 0.00 & 0.5671 & 3.3 & 0.0709 & 1.4 & 441.6 & 6.0 \\
\hline 5 & 113 & 57 & 0.52 & 6.95 & 0.37 & 0.5233 & 4.5 & 0.0713 & 1.5 & 444.2 & 6.3 \\
\hline 6 & 162 & 76 & 0.48 & 9.87 & 0.68 & 0.5538 & 5.3 & 0.0705 & 1.3 & 438.9 & 5.6 \\
\hline 7 & 129 & 57 & 0.46 & 7.88 & 0.00 & 0.5188 & 3.2 & 0.0709 & 1.4 & 441.8 & 5.9 \\
\hline 8 & 157 & 86 & 0.57 & 9.52 & 0.16 & 0.5012 & 3.1 & 0.0706 & 1.3 & 439.5 & 5.5 \\
\hline 9 & 103 & 50 & 0.50 & 6.17 & 0.00 & 0.5340 & 3.4 & 0.0699 & 1.4 & 435.4 & 6.0 \\
\hline 10 & 157 & 97 & 0.64 & 9.37 & 0.11 & 0.5218 & 3.4 & 0.0694 & 1.9 & 432.3 & 7.8 \\
\hline 11 & 128 & 70 & 0.56 & 7.82 & 0.18 & 0.5064 & 3.3 & 0.0708 & 1.3 & 441.0 & 5.7 \\
\hline 12 & 150 & 94 & 0.65 & 9.02 & 0.00 & 0.5285 & 2.8 & 0.0699 & 1.3 & 435.4 & 5.4 \\
\hline 13 & 124 & 66 & 0.55 & 7.53 & 0.23 & 0.5224 & 3.5 & 0.0708 & 1.4 & 441.2 & 5.8 \\
\hline
\end{tabular}

a) ${ }^{206} \mathrm{~Pb}^{*}$ 为放射性 ${ }^{206} \mathrm{~Pb}$ 的量 ${ }^{206} \mathrm{~Pb}_{\mathrm{C}}$ 为普通 ${ }^{206} \mathrm{~Pb}$ 占总 ${ }^{206} \mathrm{~Pb}$ 的百分比; 普通 $\mathrm{Pb}$ 用实测 ${ }^{204} \mathrm{~Pb}$ 校正 

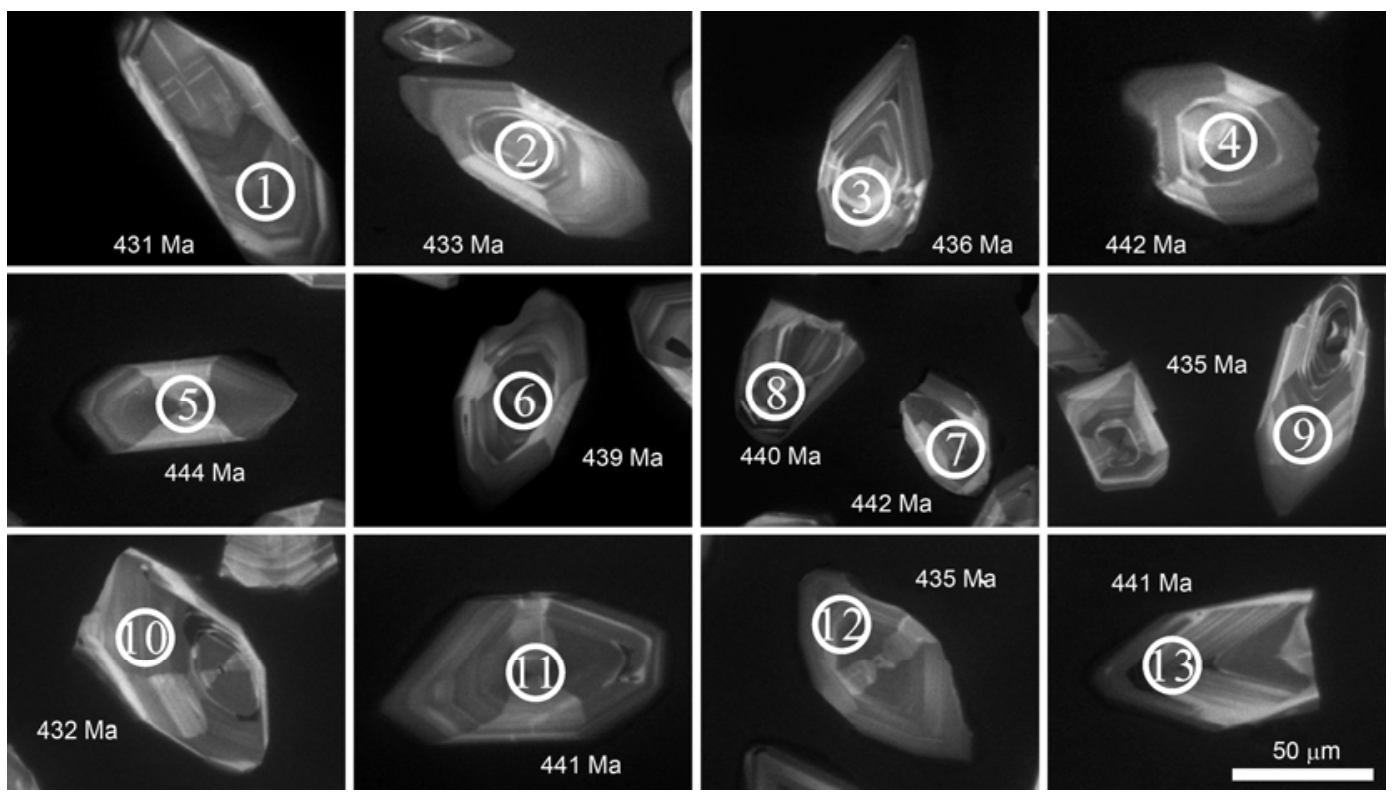

图 3 鳌油沟花岗岩锆石的阴极发光图像及全部测点的年龄
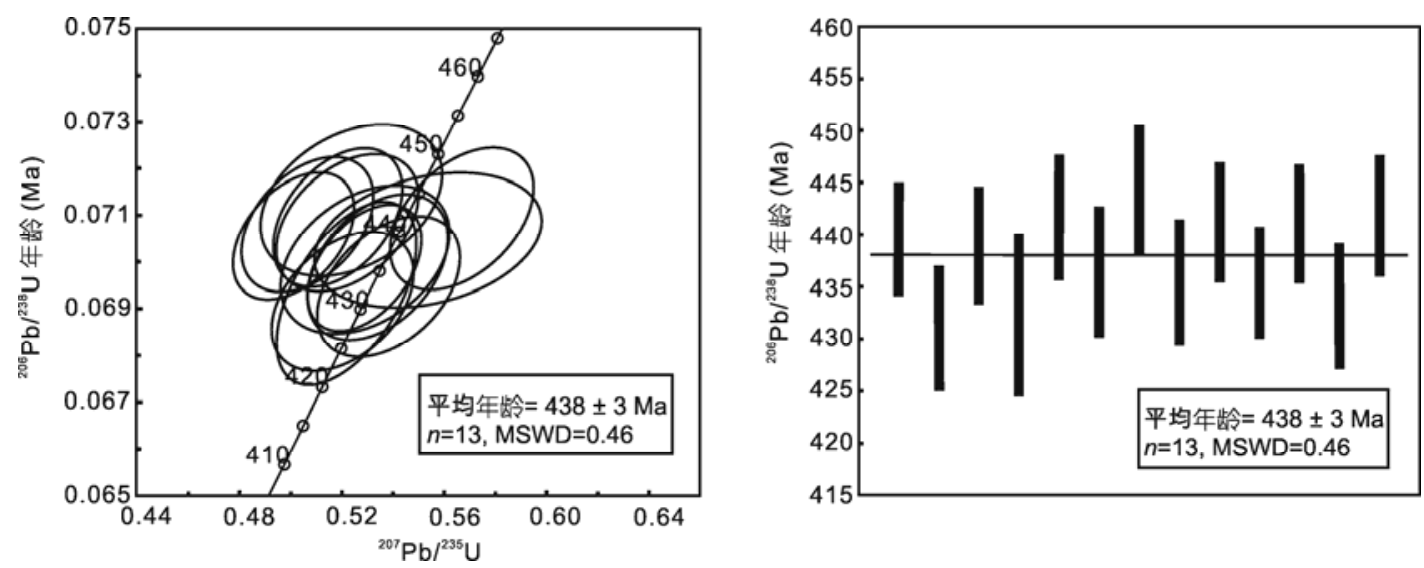

图 4 謷油沟奥长花岗岩锆石 SHRIMP U-Pb 谐和图与均值图

\section{4 地球化学特征}

\section{1 分析方法}

全岩的主量和微量元素含量分析均在中国地质大 学(北京)科学研究院地学实验中心完成. 全岩主量元 素使用 LeemanICP-OES 进行测定, 除 $\mathrm{TiO}_{2}(\sim 1.5 \%)$ 和 $\mathrm{P}_{2} \mathrm{O}_{5}(2.0 \%)$ 外, 其他元素的测量误差小于 $1 \%$. 烧 失量是根据 $1 \mathrm{~g}$ 粉末在 $1000^{\circ} \mathrm{C}$ 的烘干箱恒温放置 $4 \sim 5 \mathrm{~h}$ 后取出测得. 微量元素利用 Agilent-7500a 型 ICP-MS 进行测定. 样品的溶解、测试流程、分析精度和标样 等见文献[42]中的详细描述. 样品的分析结果见表 3 .

全岩的 $\mathrm{Rb}-\mathrm{Sr}$ 及 $\mathrm{Sm}-\mathrm{Nd}$ 同位素的分离在北京大
学造山带与地壳演化教育部重点实验室完成. 称取 100 150 mg 的样品及 50 100 mg 的 BCR-2 标样, 将 其溶解于 $\mathrm{HF}$ 和 $\mathrm{HNO}_{3}$ 中, 放置大约 7 10 d, 直至样 品完全溶解, 然后通过常规的阳离子交换柱分离和 纯化, 得到 $\mathrm{Sr}$ 和 $\mathrm{Nd}$ 元素. 同位素测试在天津地质矿 产研究所的新型热电离质谱仪 Triton上完成. 具体实 验原理及流程等见文献 [43]. 测试过程中, 所测定的 JNDI 和 NBS-987 Sr 标样的 Nd-Sr 同位素比值分别为 ${ }^{143} \mathrm{Nd} /{ }^{144} \mathrm{Nd}=0.512118 \pm 6(n=5)$ 和 ${ }^{87} \mathrm{Sr} /{ }^{86} \mathrm{Sr}=0.710238 \pm 5$ $(n=3)$. 实验测得与本文样品经过同样化学处理的 BCR-2 标样的 ${ }^{143} \mathrm{Nd} /{ }^{144} \mathrm{Nd}$ 和 ${ }^{87} \mathrm{Sr} /{ }^{86} \mathrm{Sr}$ 分别为 $0.512637 \pm 6(n=2)$ 和 $0.705016 \pm 3(n=2)$. 样品的分析结果见表 4 . 
表 3 謷油沟奥长花岗岩的主量元素 $(w t \%)$ 和微量元素 $\left(\mu \mathrm{g} \mathrm{g}^{-1}\right)$ 组成

\begin{tabular}{|c|c|c|c|c|c|c|c|c|c|}
\hline 样品号 & 09AY14 & 09AY15 & 09AY16 & 09AY17 & 10QL15 & 10QL16 & 10QL20 & 10QL21 & 10QL23 \\
\hline $\mathrm{SiO}_{2}$ & 72.41 & 70.96 & 70.52 & 69.53 & 74.07 & 73.63 & 72.83 & 67.26 & 71.64 \\
\hline $\mathrm{TiO}_{2}$ & 0.15 & 0.16 & 0.17 & 0.17 & 0.16 & 0.15 & 0.16 & 0.18 & 0.16 \\
\hline $\mathrm{Al}_{2} \mathrm{O}_{3}$ & 14.98 & 14.87 & 15.39 & 16.51 & 14.52 & 14.58 & 15.17 & 18.37 & 15.25 \\
\hline $\mathrm{Fe}_{2} \mathrm{O}_{3}$ & 0.69 & 0.77 & 0.92 & 0.74 & 1.15 & 1.05 & 1.13 & 1.34 & 1.06 \\
\hline $\mathrm{MnO}$ & 0.02 & 0.02 & 0.02 & 0.01 & 0.01 & 0.01 & 0.02 & 0.02 & 0.02 \\
\hline $\mathrm{MgO}$ & 0.66 & 0.74 & 0.82 & 0.69 & 0.70 & 0.66 & 0.77 & 0.83 & 0.55 \\
\hline $\mathrm{CaO}$ & 2.23 & 2.07 & 1.36 & 0.83 & 1.33 & 1.70 & 1.41 & 2.90 & 2.43 \\
\hline $\mathrm{Na}_{2} \mathrm{O}$ & 6.04 & 6.76 & 7.89 & 9.05 & 5.02 & 4.76 & 5.32 & 5.75 & 4.77 \\
\hline $\mathrm{K}_{2} \mathrm{O}$ & 1.59 & 1.43 & 1.12 & 1.04 & 1.47 & 1.38 & 1.27 & 1.70 & 1.62 \\
\hline $\mathrm{P}_{2} \mathrm{O}_{5}$ & 0.05 & 0.06 & 0.06 & 0.06 & 0.05 & 0.05 & 0.06 & 0.06 & 0.05 \\
\hline LOI & 1.06 & 2.03 & 1.62 & 1.29 & 0.86 & 1.40 & 1.18 & 0.75 & 1.75 \\
\hline 总量 & 99.87 & 99.86 & 99.89 & 99.94 & 99.35 & 99.35 & 99.32 & 99.17 & 99.31 \\
\hline $\mathrm{K}_{2} \mathrm{O} / \mathrm{Na}_{2} \mathrm{O}$ & 0.26 & 0.21 & 0.14 & 0.12 & 0.29 & 0.29 & 0.24 & 0.30 & 0.34 \\
\hline $\mathrm{Li}$ & 2.27 & 2.13 & 3.95 & 2.22 & 0.39 & 0.55 & 0.74 & 8.30 & 0.42 \\
\hline $\mathrm{Sc}$ & 2.25 & 2.21 & 2.09 & 2.32 & 2.03 & 1.89 & 2.15 & 2.24 & 2.01 \\
\hline V & 15.40 & 16.33 & 16.22 & 15.77 & 16.81 & 16.03 & 16.80 & 17.62 & 15.59 \\
\hline $\mathrm{Cr}$ & 8.55 & 9.52 & 9.97 & 10.40 & 22.43 & 11.17 & 13.00 & 11.13 & 9.19 \\
\hline Co & 3.01 & 2.68 & 3.30 & 2.26 & 3.26 & 2.56 & 3.17 & 3.41 & 2.08 \\
\hline $\mathrm{Ni}$ & 6.17 & 6.20 & 6.88 & 6.38 & 12.89 & 6.90 & 8.02 & 7.36 & 7.41 \\
\hline $\mathrm{Cu}$ & 2.21 & 2.62 & 2.65 & 3.55 & 4.35 & 1.62 & 1.23 & 1.31 & 0.97 \\
\hline $\mathrm{Zn}$ & 94.65 & 32.68 & 40.42 & 31.02 & 28.42 & 22.38 & 26.84 & 36.88 & 23.26 \\
\hline $\mathrm{Ga}$ & 15.39 & 15.36 & 14.81 & 13.91 & 16.30 & 16.06 & 16.84 & 18.07 & 16.40 \\
\hline $\mathrm{Rb}$ & 28.18 & 33.32 & 25.02 & 25.60 & 33.66 & 36.94 & 35.65 & 40.70 & 42.06 \\
\hline $\mathrm{Sr}$ & 661 & 739 & 539 & 212 & 782 & 551 & 521 & 764 & 552 \\
\hline Y & 2.96 & 2.64 & 2.58 & 2.96 & 3.00 & 2.62 & 2.80 & 3.41 & 2.96 \\
\hline $\mathrm{Zr}$ & 80.5 & 75.6 & 91.1 & 78.8 & 108.7 & 88.9 & 97.3 & 122.5 & 89.7 \\
\hline $\mathrm{Nb}$ & 1.18 & 1.26 & 1.22 & 1.46 & 1.77 & 1.67 & 1.98 & 1.94 & 1.97 \\
\hline Cs & 0.18 & 0.33 & 0.33 & 0.21 & 0.22 & 0.46 & 0.58 & 0.69 & 0.47 \\
\hline $\mathrm{Ba}$ & 433 & 408 & 334 & 183 & 986 & 464 & 363 & 580 & 475 \\
\hline $\mathrm{La}$ & 4.83 & 4.19 & 4.90 & 4.68 & 8.08 & 5.66 & 5.80 & 6.48 & 4.84 \\
\hline $\mathrm{Ce}$ & 10.36 & 9.34 & 10.55 & 10.33 & 15.97 & 11.62 & 12.04 & 13.42 & 10.15 \\
\hline $\operatorname{Pr}$ & 1.25 & 1.14 & 1.27 & 1.23 & 1.91 & 1.42 & 1.48 & 1.65 & 1.27 \\
\hline $\mathrm{Nd}$ & 4.85 & 4.54 & 4.95 & 4.78 & 7.56 & 5.68 & 5.98 & 6.70 & 5.21 \\
\hline $\mathrm{Sm}$ & 0.99 & 1.00 & 1.00 & 1.00 & 1.33 & 1.01 & 1.09 & 1.22 & 0.99 \\
\hline $\mathrm{Eu}$ & 0.30 & 0.30 & 0.31 & 0.20 & 0.35 & 0.22 & 0.25 & 0.31 & 0.25 \\
\hline $\mathrm{Gd}$ & 0.87 & 0.83 & 0.81 & 0.84 & 1.03 & 0.79 & 0.85 & 0.99 & 0.85 \\
\hline $\mathrm{Tb}$ & 0.11 & 0.10 & 0.10 & 0.11 & 0.12 & 0.10 & 0.11 & 0.12 & 0.11 \\
\hline Dy & 0.52 & 0.49 & 0.47 & 0.57 & 0.60 & 0.51 & 0.54 & 0.64 & 0.57 \\
\hline Ho & 0.09 & 0.08 & 0.09 & 0.10 & 0.10 & 0.09 & 0.10 & 0.11 & 0.10 \\
\hline Er & 0.24 & 0.21 & 0.21 & 0.25 & 0.24 & 0.22 & 0.23 & 0.28 & 0.24 \\
\hline $\mathrm{Tm}$ & 0.04 & 0.03 & 0.03 & 0.03 & 0.03 & 0.03 & 0.03 & 0.04 & 0.03 \\
\hline $\mathrm{Yb}$ & 0.21 & 0.18 & 0.19 & 0.22 & 0.21 & 0.20 & 0.22 & 0.26 & 0.21 \\
\hline $\mathrm{Lu}$ & 0.03 & 0.03 & 0.03 & 0.03 & 0.03 & 0.03 & 0.03 & 0.04 & 0.03 \\
\hline $\mathrm{Hf}$ & 1.90 & 1.71 & 2.09 & 1.87 & 2.61 & 2.14 & 2.38 & 2.85 & 2.23 \\
\hline $\mathrm{Ta}$ & 0.08 & 0.07 & 0.08 & 0.09 & 0.13 & 0.12 & 0.13 & 0.13 & 0.17 \\
\hline $\mathrm{Pb}$ & 6.27 & 5.23 & 6.48 & 6.89 & 8.47 & 6.99 & 6.01 & 10.43 & 8.54 \\
\hline $\mathrm{Th}$ & 0.96 & 0.92 & 0.98 & 0.99 & 2.16 & 0.88 & 0.92 & 1.06 & 0.91 \\
\hline $\mathrm{U}$ & 0.43 & 0.36 & 0.42 & 0.51 & 0.61 & 0.45 & 0.49 & 0.55 & 0.48 \\
\hline $\mathrm{Sr} / \mathrm{Y}$ & 223 & 280 & 209 & 72 & 261 & 210 & 186 & 224 & 187 \\
\hline$(\mathrm{La} / \mathrm{Yb})_{\mathrm{N}}$ & 16.60 & 16.30 & 18.88 & 14.99 & 27.79 & 20.35 & 19.19 & 17.94 & 16.29 \\
\hline
\end{tabular}


表 4 奥长花岗岩的 Sr-Nd 同位素组成 ${ }^{\text {a) }}$

\begin{tabular}{|c|c|c|c|c|c|c|c|c|c|c|c|c|}
\hline 样品号 & ${ }^{87} \mathrm{Rb} /{ }^{86} \mathrm{Sr}$ & ${ }^{87} \mathrm{Sr} /{ }^{86} \mathrm{Sr}$ & $2 \sigma$ & $I_{\mathrm{Sr}}(t)$ & ${ }^{147} \mathrm{Sm} /{ }^{144} \mathrm{Nd}$ & ${ }^{143} \mathrm{Nd} /{ }^{144} \mathrm{Nd}$ & $2 \sigma$ & $t(\mathrm{Ma})$ & $\varepsilon_{\mathrm{Nd}}(0)$ & $\varepsilon_{\mathrm{Nd}}(t)$ & $f_{\mathrm{Sm} / \mathrm{Nd}}$ & $T_{\mathrm{DM} 2}$ \\
\hline 09AY-14 & 0.124 & 0.7054 & 3 & 0.7047 & 0.124 & 0.5126 & 12 & 438 & 0.05 & 4.1 & -0.37 & 836 \\
\hline 10QL-15 & 0.125 & 0.7052 & 4 & 0.7044 & 0.106 & 0.5126 & 5 & 438 & -1.25 & 3.8 & -0.46 & 869 \\
\hline 09AY-17 & 0.350 & 0.7069 & 7 & 0.7047 & 0.127 & 0.5126 & 7 & 438 & -0.96 & 3.0 & -0.36 & 932 \\
\hline
\end{tabular}
$10^{-12} \mathrm{a}^{-1}$; 二阶段模式年龄计算见文献[44]

\section{2 分析结果}

九件样品表现出高的 $\mathrm{SiO}_{2}(67.3 \mathrm{wt} \%$ 74.1 wt\%), $\mathrm{Na}_{2} \mathrm{O}$ (4.76 wt\% 9.05 wt \%), $\mathrm{Al}_{2} \mathrm{O}_{3}$ (14.5 wt\% 18.4 $\mathrm{wt} \%)$; 低的 $\mathrm{MgO}(0.55 \mathrm{wt} \% \sim 0.83 \mathrm{wt} \%), \mathrm{CaO}(0.83$ ${ }_{\mathrm{wt}} \%$ 2.90 wt\%), $\mathrm{K}_{2} \mathrm{O}(1.04 \mathrm{wt} \% \sim 1.70 \mathrm{wt} \%)$ 及极低的 $\mathrm{K}_{2} \mathrm{O} / \mathrm{Na}_{2} \mathrm{O}$ 比值 $(0.12 \sim 0.34)$ 等特点. 在 $\mathrm{K}-\mathrm{Na}-\mathrm{Ca}$ 三角 图解(图 5)中, 所有样品均落人太古代 TTG 区域, 并 且与奥长花岗质岩浆演化趋势具有亲和性. 在 $\mathrm{K}_{2} \mathrm{O}-$ $\mathrm{SiO}_{2}$ 图解(图 6(a)) 上, 样品点主要分布于低钾拉斑玄 武岩系列和钙碱性系列之间和现代俯冲带中埃达克 岩区域之内，而明显低于中国华北型埃达克岩.

与 Martin 等人 ${ }^{[8]}$ 划分的低硅埃达克岩(LSA)与高 硅埃达克岩(HSA)相比, 除 09AY-17 样品具有相对低 的 $\mathrm{Sr}$ 导致其落在 HSA 区域外, 其余 8 个样品均投影 在 HSA 范围内(图 6((a) (h))). 这些样品表现出 LREE 富 集 HREE 亏损 $\left((\mathrm{Yb})_{\mathrm{N}}=0.18 \sim 0.26 \mu \mathrm{g} \mathrm{g}^{-1} ;(\mathrm{La} / \mathrm{Yb})_{\mathrm{N}}=16.3 \sim\right.$ 27.8), 高 $\operatorname{Sr}\left(521 \sim 782 \mu \mathrm{g} \mathrm{g}^{-1}\right)$, 低 $\mathrm{Y}\left(2.58 \sim 3.41 \mu \mathrm{g} \mathrm{g}^{-1}\right)$, 高 $\mathrm{Sr} / \mathrm{Y}$ 值(186 280), Eu 无异常等特征, 类似于埃达

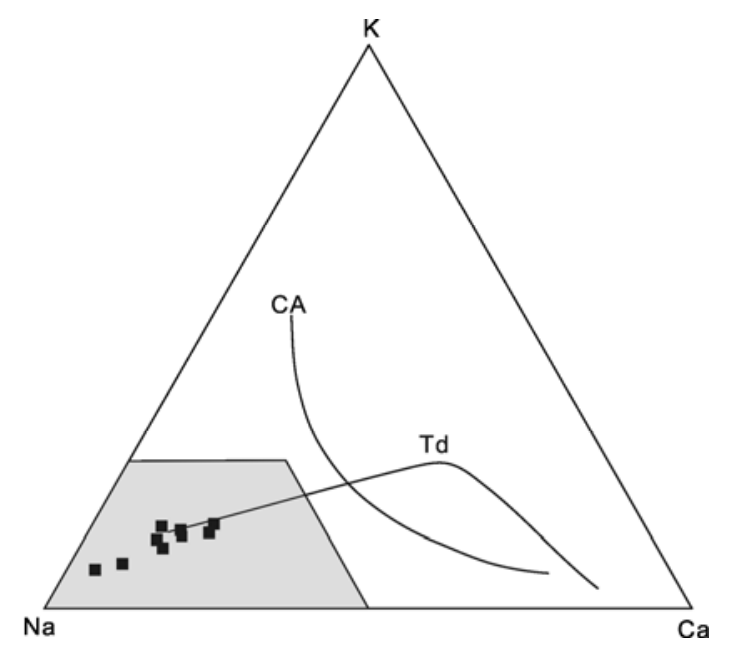

图 5 K-Na-Ca 三角图解 ${ }^{[55]}$

$\mathrm{CA}$, 岛弧区钻碱性岩浆演化趋势; $\mathrm{Td}$, 奥长花岗质岩浆演化趋势; 灰 色区域, 太古代 TTG 投影区, 引自文献[46]
克岩. 在原始地幔标准化的微量元素蛛网图上, 所有 样品均显示出明显的 $\mathrm{Pb}, \mathrm{Sr}, \mathrm{Zr}, \mathrm{Hf}$ 正异常, 高场强元 素 Nb, Ta, Ti 负异常 (图 7(a)); 球粒陨石标准化的稀 土元素配分曲线为明显的右倾陡斜状 (图 7(b)). 在 $\mathrm{Sr} / \mathrm{Y}-\mathrm{Y}$ 和 $(\mathrm{La} / \mathrm{Yb})_{\mathrm{N}}-\mathrm{Yb}_{\mathrm{N}}$ 判别图解(图 8)上, 样品点均 落在埃达克岩区域内, 明显不同于正常的岛弧钙碱 性岩浆 ${ }^{[1]}$. 09AY-17 样品具有高 $\mathrm{Na}_{2} \mathrm{O}$ 、相对低的 $\mathrm{CaO}$ 和 $\mathrm{Sr}$ 含量 $\left(212 \mu \mathrm{g} \mathrm{g}^{-1}\right)$ 及 $\mathrm{Sr} / \mathrm{Y}$ 比值(72), 并具有微弱 的 $\mathrm{Eu}$ 负异常, 可能是由于岩浆结晶分异过程中斜长 石分离结晶的结果.

三件奥长花岗岩样品的 ${ }^{87} \mathrm{Sr} /{ }^{86} \mathrm{Sr}$ 和 ${ }^{143} \mathrm{Nd} /{ }^{144} \mathrm{Nd}$ 比值分别为 $0.7054 \sim 0.7069$ 和 0.5126 0.5126 (表 4). 假定奥长花岗岩的形成年龄为 $438 \mathrm{Ma}$ (见下文) 及 根据所测得的微量元素 $\mathrm{Rb} / \mathrm{Sr}$ 和 $\mathrm{Sm} / \mathrm{Nd}$ 比值, 可计 算出该奥长花岗质岩浆的初始 $\mathrm{Sr}$ 比值 $I_{\mathrm{Sr}}$ 为 $0.7044 \sim$ $0.7047, \varepsilon_{\mathrm{Nd}}(t)$ 值为 $+3.0 \sim+4.1$, 二阶段 $\mathrm{Nd}$ 模式年龄 $\left(T_{\mathrm{DM} 2}\right)$ 为 836 932 Ma.

\section{5 讨论}

北祁连山榴辉岩的形成年龄为 $460 \sim 490 \mathrm{Ma}^{[33,48,49]}$, 蓝片岩中蓝闪石和多硅白云母的 $\mathrm{Ar}-\mathrm{Ar}$ 年龄集中在 440 460 $\mathrm{Ma}^{[50 \sim 52]}$. 结合区内花岗岩以及广泛发育有 志留纪海盆相复理石建造和泥盆纪磨拉石等现象, 一般认为北祁连古大洋的消亡和闭合时间为晚奥陶

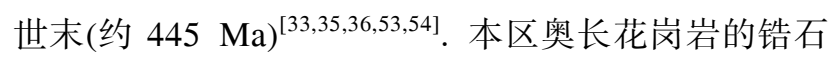
$\mathrm{U}-\mathrm{Pb}$ 同位素 SHRIMP 年龄为 $438 \pm 3 \mathrm{Ma}$, 明显晚于榴 辉岩和蓝片岩的形成年龄, 而接近于北祁连古大洋 的消亡时间，暗示其形成与北祁连古大洋的闭合以 及大陆碰撞有着密切的联系.

实验岩石学已证明, 变质基性岩在石榴石稳定域 内(至少在 $1.0 \mathrm{GPa}$ 以上)可以产生埃达克质熔体 ${ }^{[55 ~ 57]}$. 根据源岩及形成机制的不同，一般认为埃达克岩的 成因模式主要有以下 3 种: (1) 俯冲板片部分熔融的 产物 $^{[1 \sim 6,14]} ;$ (2) 加厚下地壳部分熔融的产物 ${ }^{[15 ~ 21,25] ; ~}$ 

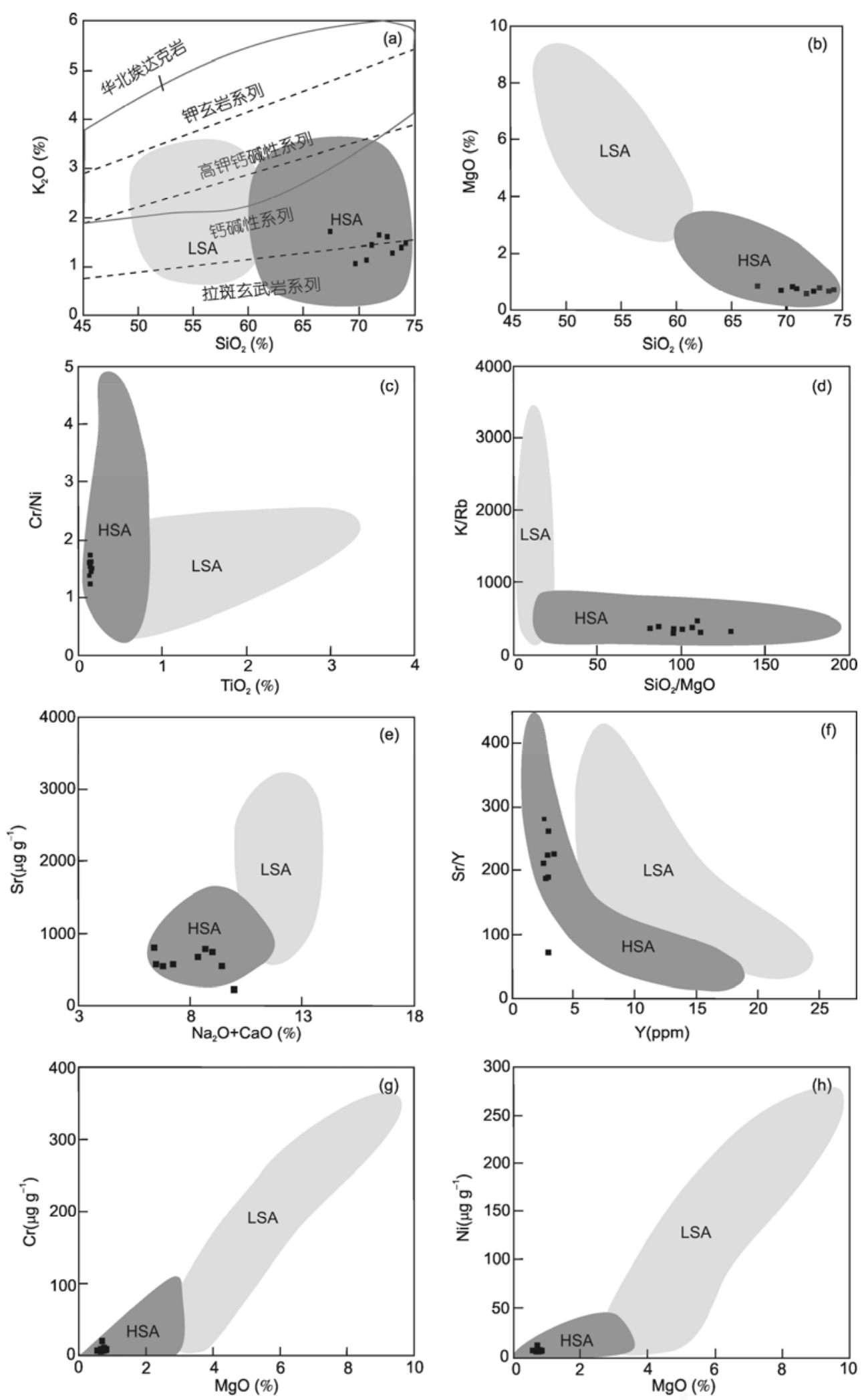

图 6 主量元素和微量元素相关图解

(a) $\mathrm{K}_{2} \mathrm{O}-\mathrm{SiO}_{2}$; (b) $\mathrm{MgO}_{-} \mathrm{SiO}_{2}$; (c) Cr/Ni-TiO ${ }_{2}$; (d) $\mathrm{K} / \mathrm{Rb}-\mathrm{SiO}_{2} / \mathrm{MgO}$; (e) $\mathrm{Sr}-\mathrm{Na}_{2} \mathrm{O}+\mathrm{CaO}$; (f) $\mathrm{Sr} / \mathrm{Y}-\mathrm{Y}$; (g) Cr-MgO; (h) Ni-MgO. 浅灰色为低硅埃达克岩 (LSA)范围, 深灰色为高硅埃达克岩 $(H S A)$ 范围 ${ }^{[8]} ;$ (a)中实线区域为华北埃达克岩范围 ${ }^{[21]}$ 

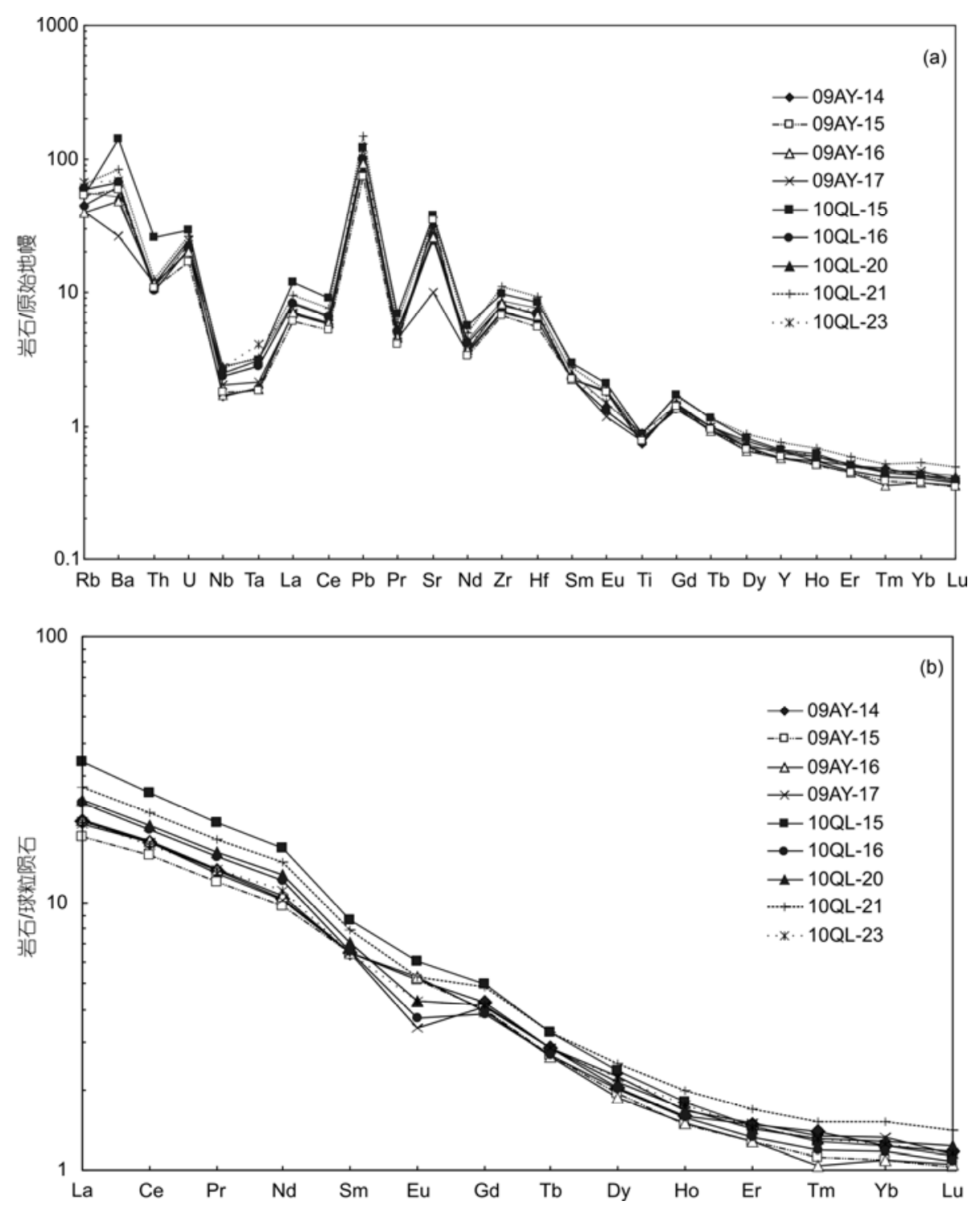

图 7 謷油沟奥长花岗岩的微量元素(a)和稀土元素(b)配分图解 标准化数据引自文献[47]
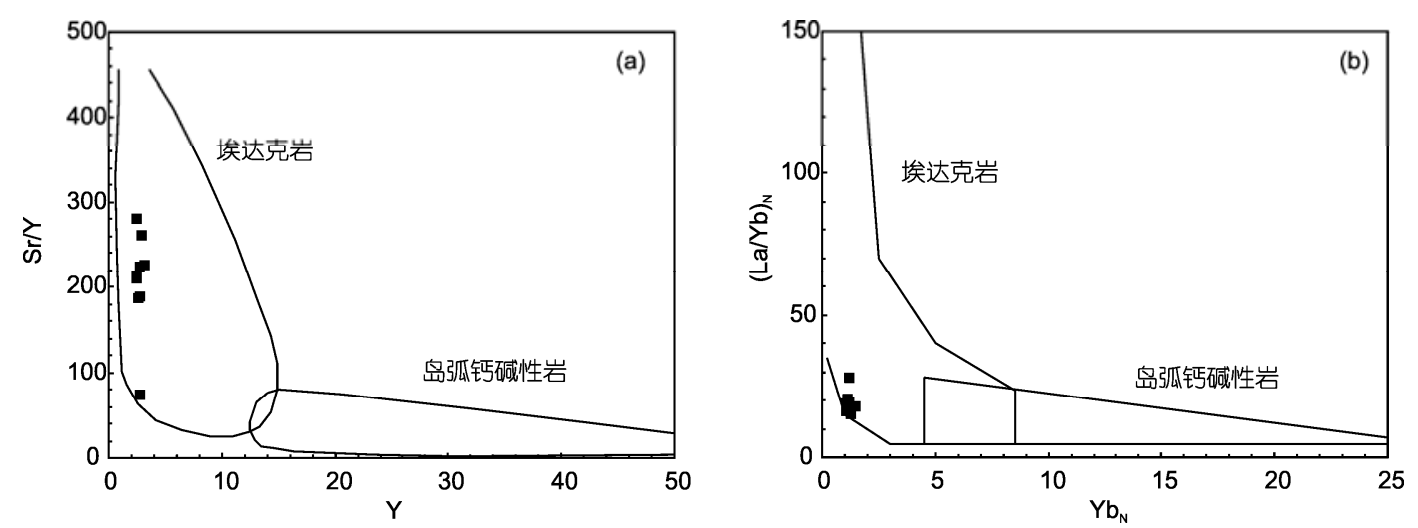

图 8 謷油沟花岗岩的 $\mathrm{Sr} / \mathrm{Y}-\mathrm{Y}(\mathrm{a})$ 和 $(\mathrm{La} / \mathrm{Yb})_{\mathrm{N}}-\mathrm{Yb} \mathrm{b}_{\mathrm{N}}(\mathbf{b})$ 图解 
（3）玄武质母岩浆高压结晶分异的结果 ${ }^{[22,24]}$. 㥿油沟 奥长花岗岩样品的 $\mathrm{Sr}$ 初始值 $I_{\mathrm{Sr}}$ 和 $\varepsilon_{\mathrm{Nd}}(t)$ 值分别为 0.7044 0.7047 和 +3.0 +4.1, 暗示其来源于新生的地 壳物质, 而非古老下地壳部分熔融产物. 所有样品富 钠贫钾, 其 $\mathrm{K}_{2} \mathrm{O} / \mathrm{Na}_{2} \mathrm{O}$ 比值(0.12 0.34) 明显低于下地 壳成因的埃达克岩(接近 0.5 ), 暗示其源岩不可能是 大陆下地壳部分熔融的产物. Sr-Nd 同位素特征也显 示本文样品与这些下地壳成因的埃达克质岩石(如西 藏、北祁连中段、科罗迪亚等地)有明显差别(图 9). 相 比一些亏损洋壳来源的埃达克岩, 本文样品虽然显 示出 Sr-Nd 同位素略富集特征, 但与受到大洋沉积物 影响的洋壳熔融成因的埃达克岩(如 Austral Volcanic Zone 和 Tonga 地区)基本一致 ${ }^{[14,58]}$, 而且 $\mathrm{Nd}$ 同位素 与造山带中大洋俯冲形成的榴辉岩(如柴北缘(图 9) 和阿尔卑斯洋壳变质榴辉岩 $(+2.3 \sim+7.8)$ )相接近 ${ }^{[62,63]}$. 在微量元素组成上, 岛弧玄武岩(IAB)具有明显富集 大离子亲石元素和轻稀土元素的特征, 而洋中脊玄 武岩(MORB)则表现为亏损大离子亲石元素和轻稀土 元素. 弧后盆地玄武岩在微量元素组成上可以兼具 IAB 型和 MORB 型分布特点 ${ }^{[64 ~ 66]}$, 取决于部分熔融
的时间和位置(一般早期的为 IAB 型, 晚期的变成 MORB 型). 本文样品中轻稀土元素和大离子亲石元 素相对富集程度较弱 ((La) $\left.)_{\mathrm{N}}=18 \sim 34\right)$ (图 7(b)), 类似于 富集型洋中脊玄武岩(E-MORB), 说明其不大可能是 典型岛弧玄武岩部分熔融的产物，而可能是弧后盆 地发育中期阶段所形成的玄武岩. 由这类洋壳玄武 岩部分熔融, 就能够产生具有长英质化学成分、相对 亏损 Sr-Nd 同位素、类似于 E-MORB 微量元素组成 的花岗岩. 因此, 謷油沟奥长花岗岩可能是俯冲板片 部分熔融的产物.

\section{1 热源}

众所周知，俯冲板片发生部分熔融取决于俯冲 带是否有足够的热源. 一些特殊的俯冲环境, 如高的 地热梯度、热的年轻板片、快速/平缓俯冲、板片窗 等, 可以导致变基性岩中含水矿物的脱水熔融 ${ }^{[1,6,26]}$. 与北祁连山中段广泛发育的岛弧火山杂岩和高压变 质岩(含硬柱石蓝片岩及榴辉岩 ${ }^{[33,51,67]}$ )相比, 北祁连 山西段謷油沟附近尚未发现有高压变质岩或岛弧火 山岩. 这可能是低角度俯冲的结果, 类似于日本岛弧

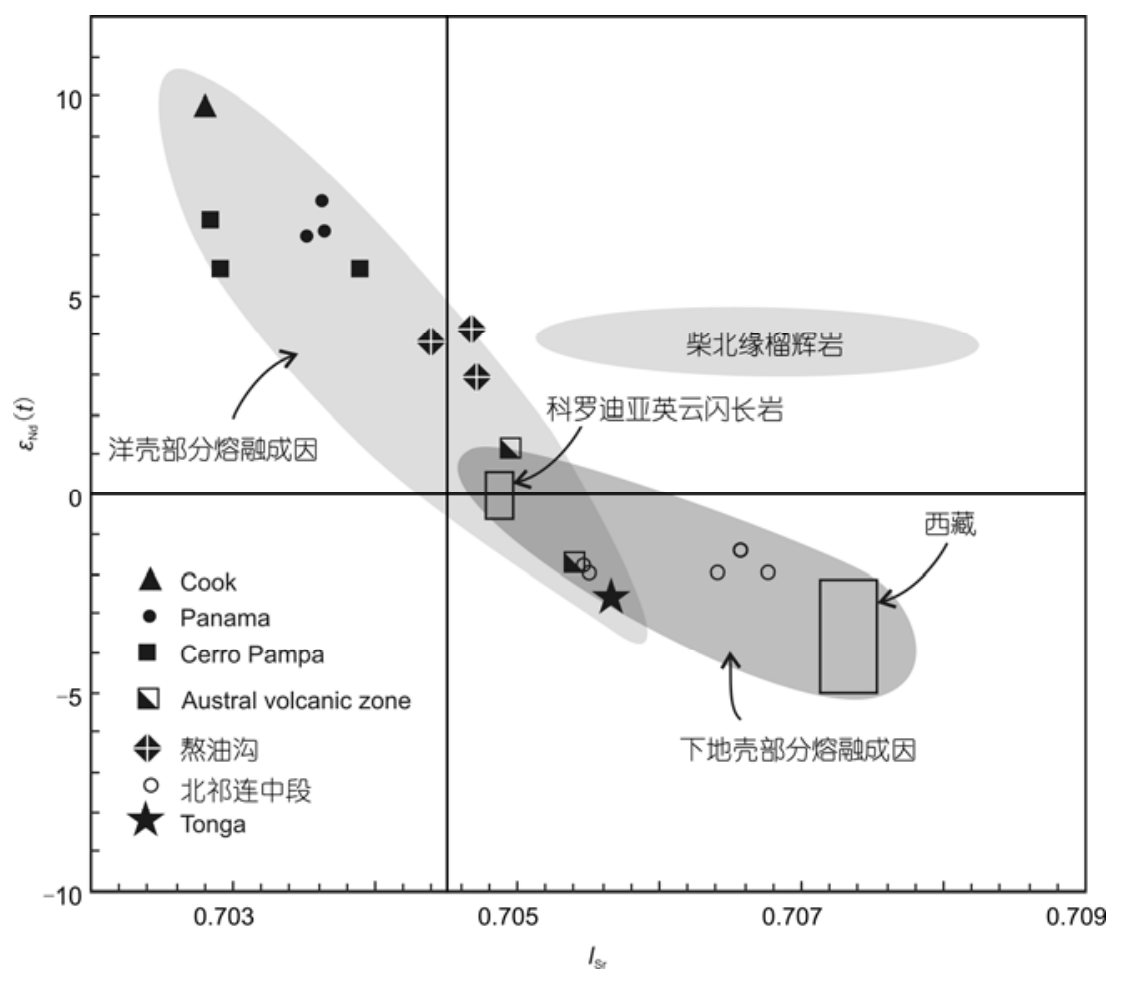

图 9 謷油沟奥长花岗岩 $\mathbf{S r}-\mathrm{Nd}$ 同位素

数据来源: 俯冲板片熔融成因 ${ }^{[4,14,58,59]}$; 下地壳熔融成因 ${ }^{[25,60,61]}$; 柴北缘榴辉岩 ${ }^{[62]}$ 
南部的构造环境 ${ }^{[8,69]}$.

经典的板片熔融成因模式认为, 当板片向下俯 冲时, 玄武质洋壳由绿片岩相经角闪岩相转变为榴 辉岩相的过程是一个含水矿物脱水的过程. 当板片 足够热时, 其结果不再是脱流体而是生成熔体. 加压 升温虽是熔体形成的一个重要条件, 减压脱水同样 有助于熔体的生成 ${ }^{[70]}$. 野外岩石学观察和 P-T 相图 模拟计算证明，在折返过程中含水矿物分解可以引 起减压熔融 ${ }^{[28 ~ 31]}$. Nahodilova 等人 ${ }^{[32]}$ 在研究中欧 Moldanubian 带中发育浅色条带的酸性麻粒岩时, 发 现高压变质岩由早期榴辉岩相到麻粒岩相升温降压 过程可生成高达 $26 \%$ 的熔体. Zhao 等人 ${ }^{[71]}$ 对苏鲁造 山带东部晚三叠世花岗岩的研究得到, 这些岩石是 深俯冲大陆地壳(超高压变质岩)折返过程中部分熔 融的产物. 謷油沟奥长花岗岩的结晶年龄比榴辉岩 的形成年龄大约晚 20 50 Ma, 其形成时代可能与榴 辉岩折返时间相当. 因此, 本文研究的奥长花岗岩很 可能是榴辉岩在折返过程中减压熔融形成的.

\section{2 压力}

所有埃达克岩均富集 LILE, Pb 和 LREE, 亏损 $\mathrm{Nb}, \mathrm{Ta}, \mathrm{Ti}$ 和 HREE, 具有高 $\mathrm{Sr} / \mathrm{Y}$ 值 $(>40)$. 高 $\mathrm{Sr} / \mathrm{Y}$ 比 值和 HREE 亏损的特点通常被解释为熔融发生在石 榴石稳定区的深度. 本文 9 个样品均具有典型的高 $\mathrm{Sr} / \mathrm{Y}$ 、轻重稀土分馏明显、 $\mathrm{Sr}$ 正异常，暗示其形成深 度在石榴石稳定存在的范围内. 随着实验岩石学的 发展, 金红石被认为也是埃达克质熔体形成的必要 残留相. Foley 等人 ${ }^{[72]}$ 根据金红石/熔体的分配系数 $D_{\mathrm{Ta}}>D_{\mathrm{Nb}}$, 认为金红石的残留将导致熔体具有更高的 $\mathrm{Nb} / \mathrm{Ta}$ 比值，从而否认金红石的存在. 但是随后的实 验结果证明, 金红石仅仅导致熔体相 $\mathrm{Nb} / \mathrm{Ta}$ 值非常微 弱的增加, 并且残留的金红石很好地解释了埃达克 岩中 $\mathrm{Nb}, \mathrm{Ta}$ 负异常的现象 ${ }^{[21,73 \sim 75]}$. 本文 9 个样品均表 现出明显的 $\mathrm{Nb}, \mathrm{Ta}, \mathrm{Ti}$ 负异常现象, 暗示了本区样品 的源区有金红石残留. 根据金红石稳定存在的压力 范围为大于 $1.5 \mathrm{GPa}$, 可以推断样品形成的压力应该 在 $1.5 \mathrm{GPa}$ 之上 ${ }^{[21,75]}$. 另外, Moyen ${ }^{[76]}$ 通过模拟计算 指出, 在角闪岩发生部分熔融时, 只有压力超过 1.5 $\mathrm{GPa}$, 残留矿物相有石榴石出现时, 其产生的熔体 $\mathrm{Sr} / \mathrm{Y}$ 值相对源区才能高出 10 倍以上. 洋壳的 $\mathrm{Sr} / \mathrm{Y}$ 比 值一般为 $2 \sim 10$, 据此我们简单推断, 要形成本区样
品如此高 $\mathrm{Sr} / \mathrm{Y}$ 比值 (除了 09AY-17 外, 其余 8 个样 品的 $\mathrm{Sr} / \mathrm{Y}$ 比值平均为 222.5), 其压力应至少为 $1.8 \mathrm{GPa}$, 形成深度至少 $60 \mathrm{~km}^{[76]}$.

\section{3 与地幔楔的交代程度}

已有资料表明, 俯冲大洋板片熔融形成的埃达 克质熔体在上升的过程中, 只要经过地幔楔, 与地幔 橄榄岩发生交代平衡, 通常要留下比实验熔体更高 的 $\mathrm{MgO}, \mathrm{Ni}, \mathrm{Cr}$ 含量的记录 ${ }^{[57,77]}$. 类似于太古代 TTG 岩石, 本区样品表现出低的 $\mathrm{MgO}, \mathrm{Ni}, \mathrm{Cr}$ 含量(图 4((g), (h))), 暗示熔体在上升过程中与地幔楔发生交代程度 非常有限, 被解释为俯冲深度较浅的结果 ${ }^{[7,11,14]}$. 除 此之外, 我们认为可能的原因有二. 第一, 根据 Rapp 等人 ${ }^{[77]}$ 提出的 $a=$ 有效熔体/地幔橄榄岩这一概念, 假 设俯冲板片产生的熔体足够多, 即 $a$ 越大, 如果熔体 在上升过程中经过地幔楔, 则先形成的埃达克质熔 体由于与地幔楔发生交代平衡, 应具有低硅、高 $\mathrm{MgO}$, $\mathrm{Ni}, \mathrm{Cr}$ 的特点; 而后形成的埃达克质熔体可沿原先的 岩浆通道上升, 从而限制了熔体与地幔楔的接触程 度, 导致地幔楔对熔体的影响非常有限, 形成的埃达 克岩具有相对较高的硅、低 $\mathrm{MgO}, \mathrm{Ni}, \mathrm{Cr}$ 的特征. 第 二, 謷油沟埃达克岩可能是榴辉岩折返过程中减压 熔融的产物, 如果熔体随着榴辉岩的折返路径, 即沿 俯冲板片与上覆板片的接触界面向上迁移直至最终 岩浆侵位、结晶, 则可避免与地幔楔的交代平衡作用, 形成低 $\mathrm{MgO}, \mathrm{Ni}, \mathrm{Cr}$ 特征的埃达克岩.

\section{6 结论}

（1）謷油沟花岗岩具有高 $\mathrm{SiO}_{2}(69.5 \%$ 72.4\%), 富 $\mathrm{Na}$ 贫 $\mathrm{K}$, 高 $\mathrm{Sr} / \mathrm{Y},(\mathrm{La} / \mathrm{Yb})_{\mathrm{N}}, \mathrm{Sr}$ 正异常, $\mathrm{Eu}$ 无或弱 的负异常等特征, 类似于高硅埃达克岩, 具有与太古 代奥长花岗岩相似 (低 $\mathrm{MgO}, \mathrm{Ni}, \mathrm{Cr}$ ) 的地球化学特 征; Sr-Nd 同位素结果显示其 $I_{\mathrm{Sr}}$ 和 $\varepsilon_{\mathrm{Nd}}(t)$ 值分别为 0.7044 0.7047 和+3.0 +4.1, 暗示其来源于新生的洋 壳玄武岩.

(2) 锆石的 SHRIMP 定年结果为 $438 \pm 3 \mathrm{Ma}$, 明 显晚于岛弧火山岩和高压变质岩的年龄, 暗示其形 成与高压变质岩的折返有关.

(3) 謷油沟奥长花岗岩的可能成因是在约 460 490 $\mathrm{Ma}$ 时, 俯冲板片变质成为榴辉岩后, 在约 $438 \mathrm{Ma}$ 时, 折返的榴辉岩在大于 $60 \mathrm{~km}$ 处发生减压熔融的结果. 
致谢锆石定年过程中得到中国地质科学院刘敦一先生和颉硕强博士的帮助, 全岩地球化学分析得到中国地质大学苏 犁教授及其研究生的帮助. Martin H. 提供高硅和低硅埃达克岩的数据, 郑永飞教授和两位评审人对本文提出了 中肯和建设性的修改意见, 在此深表谢忱.

\section{参考文献}

1 Defant M J, Drummond M S. Derivation of some modern arc magmas by melting of young subducted lithosphere. Nature, 1990, 347: $662-665$

2 Kay R W. Aleutian magnesian andesites: Melts from subducted Pacific ocean crust. J Volcanol Geoth Res, 1978, 4: 117-132

3 Defant M J, Clark L F, Stewart R H, et al. Andesite and dacite genesis via contrasting processes: The geology and geochemistry of E1 Valle Volcano, Panama. Contrib Mineral Petrol, 1991, 106: 309-324

4 Defant M J, Jackson T E, Drummond M S, et al. The geochemistry of young volcanism throughout western Panama and southeastern Costa Rica: An overview. J Geol Soc London, 1992, 149: 569-579

5 Yogodzinski G M, Kelemen P B. Slab melting in Aleutians: Implications of an ion probe study of clinopyroxene in primitive adakite and basalt. Earth Planet Sci Lett, 1998, 158: 53-65

6 Yogodzinski G M, Lees J M, Churikova T G, et al. Geochemical evidence for the melting of subducting oceanic lithosphere at plate edges. Nature, 2001, 409: 500-504

7 Martin H. Adakitic magmas: Modern analogues of Archaean granitoids. Lithos, 1999, 46: 411-429

8 Martin H, Smithies R H, Rapp R, et al. An overview of adakite, tonalite-trondhjemite-granodiorite (TTG), and sanukitoid: Relationships and some implications for crustal evolution. Lithos, 2005, 79: 1-24

9 Smithies R H. The Archaean tonalite-trondhjemite-granodiorite (TTG) series is not an analogue of Cenozoic adakite. Earth Planet Sci Lett, 2000, 182: 115-125

10 Condie K C. TTGs and adakites: Are they both slab melts? Lithos, 2005, 80: 33-44

11 Naqvi S M, Rana Prathap J G. Geochemistry of adakites from Neoarchaean active continental margin of Shimoga schist belt, Western Dharwar Craton, India: Implications for the genesis of TTG. Precambrian Res, 2007, 156: 32-54

12 Naqvi S M, Mohan M R, Rana Prathap J G, et al. Adakite-TTG connection and fate of Mesoarchaean basaltic crust of Holenarsipur Nucleus, Dharwar Craton, India. J Asian Earth Sci, 2009, 35: 416-434

13 Sajona F G, Maury R C, Bellon H, et al. Initiation of subduction and the generation of slab melts in western and eastern Mindanao, Philippines. Geology, 1993, 21: 1007-1010

14 Falloon T J, Danyushevsky L V, Crawford A J, et al. Boninites and adakites from the northern termination of the Tonga trench: Implications for adakite petrogenesis. J Petrol, 2008, 49: 697-715

15 Hou Z Q, Gao Y F, Qu Z Y, et al. Origin of adakitic intrusives generated during mid-Miocene east-west extension in southern Tibet. Earth Planet Sci Lett, 2004, 220: 139-155

16 Chung S L, Liu D Y, Ji J Q, et al. Adakites from continental collision zones: Melting of thickened lower crust beneath southern Tibet. Geology, 2003, 31: 1021-1024

17 Gao S, Rudnick R L, Yuan H L, et al. Recycling lower continental crust in the North China Craton. Nature, 2004, 432: 892-897

18 Xu W L, Wang Q H, Wang D Y, et al. Mesozoic adakitic rocks from the Xuzhou-Suzhou area, eastern China: Evidence for partial melting of delaminated lower continental crust. J Asian Earth Sci, 2006, 27: 454-464

19 张旗, 王焰, 钱青, 等. 中国东部燕山期埃达克岩的特征及其构造-成矿意义. 岩石学报, 2001, 17: 236-244

20 张旗，许继峰，王焰，等. 埃达克岩的多样性. 地质通报, 2004, 23: 959-965

21 张旗，王焰，熊小林，等. 埃达克岩和花岗岩：挑战与机遇. 北京：中国大地出版社, 2008. 19-68

22 Macpherson C G, Dreher S T, Thirwall M F. Adakites without slab melting: High pressure processing of island arc Magma, Mindanao, the Philippines. Earth Planet Sci Lett, 2006, 243: 581-593

23 Castillo P R. 埃达克岩成因回顾. 科学通报, 2006, 51: 617-627

24 Castillo P R, Janney P E, Solidum R U. Petrology and geochemistry of Camiguin Island, southern Philippines: Insights into the source of adakites and other lavas in a complex arc setting. Contrib Mineral Petrol, 1999, 134: 33-51

25 Tseng C Y, Yang H J, Yang H Y, et al. Continuity of the North Qilian and North Qinling orogenic belts, Central Orogenic System of China: Evidence from newly discovered Paleozoic adakitic rocks. Gondwana Res, 2009, 16: 285-293

26 Gutscher M A, Maury R, Eissen J P, et al. Can slab melting be caused by flat subduction? Geology, 2000, 28: 535-538 
27 Winter J D. An Introduction to Igneous and Metamorphic Petrology. 2nd ed. New York: Prentice Hall, 2010

28 Sisson T W, Bronto S. Evidence for pressure-release melting beneath magmatic arcs from basalt at Galunggung, Indonesia. Nature, 1998, 391: $883-886$

29 Carson C J, Powell R, Wilson C J L, et al. Partial melting during tectonic exhumation of a granulite terrane: an example from the Larsemann Hills, East Antarctica. J Metamorph Geol, 1997, 15: 105-126

30 Bhattacharya S. Archean high-T decompression and partial melting in the Eastern Ghats Belt, India: Correlation with the Antarctic Napier Complex. Gondwana Res, 2001, 4: 575-576

31 Norlander B H, Whitney D L, Teyssier C, et al. Partial melting and decompression of the Thor-Odin dome, Shuswap metamorphic core complex, Canadian Cordillera. Lithos, 2002, 61: 103-125

32 Nahodilova R, Faryad S W, Dolejs D, et al. High-pressure partial melting and melt loss in felsic granulites in the Kutna Hora complex, Bohemian Massif (Czech Republic). Lithos, 2011, 125: 641-658

33 Song S G, Zhang L F, Niu Y L, et al. Evolution from oceanic subduction to continental collision: A case study of the Northern Tibetan Plateau inferred from geochemical and geochronological data. J Petrol, 2006, 47: 435-455

34 冯益民，何世平．祁连山大地构造与造山作用．北京：地质出版社, 1996

35 Song S G, Niu Y L, Zhang L F, et al. Tectonic evolution of Early Paleozoic HP metamorphic rocks in the North Qilian Mountains, NW China: New perspectives. J Asian Earth Sci, 2009, 35: 334-353

36 Song S G, Niu Y L, Su L, et al. Tectonics of the North Qilian Orogen, NW China. Gondwana Res, 2012, doi: 10.1016/j.gr.2012.02.004

37 肖序常, 陈国铭, 朱志直. 祁连山古蛇绿岩带的地质意义. 地质学报, 1978, 52: 287-295

38 相振群, 陆松年, 李怀坤, 等. 北祁连西段謷油沟辉长岩的锆石 SHRIMP U-Pb 年龄及地质意义. 地质通报, 2007, 26: 1686-1691

39 Ludwig K R. Users Manual for Isoplot/Ex rev. 2.49. Berkeley Geochronology Centre, 2001, 1: 56

40 宋彪, 张玉海, 刘敦一. 微区原位分析仪器 SHRIMP 的产生与锆石同位素地质年代学. 质谱学报, 2002, 23: 58-62

41 Williams I S. U-Th-Pb geochronology by ion microprobe. Rev Ecol Geol, 1998, 7: 1-35

42 Song S G, Su L, Li X H, et al. Tracing the 850-Ma continental flood basalts from a piece of subducted continental crust in the North Qaidam UHPM belt, NW China. Precambrian Res, 2010, 183: 805-816

43 Jahn B M, Cornichet J, Cong B, et al. Ultrahigh- $\varepsilon_{\mathrm{Nd}}$ eclogites from an ultrahigh-pressure metamorphic terrane of China. Chem Geol, 1996, 127: $61-79$

44 Li X H, Li Z X, Ge W C, et al. Neoproterozoic granitoids in South China: Crustal melting above a mantle plume at ca. 825 Ma? Precambrian Res, 2003, 122: 45-83

45 Barker F, Arth J G. Generation of trondhjemitic-tonalitic liquids and Archaean bimodal trondhjemite-basalt suites. Geology, 1976, 4: 596-600

46 Martin H. The Archaean grey gneisses and the genesis of the continental crust. Archaean Crust Evol, 1995, 205-259

47 Sun S S, McDonough W F. Chemical and isotopic systematics of oceanic basalt: Implications for Mantle composition and processes. In: Saunders A D, Norry M J, eds. Magmatism in the Ocean Basins. Geol Soc Spec Publ, 1989, 42: 528-548

48 宋述光, 张立飞, Niu Y, 等. 北祁连山榴辉岩锆石 SHRIMP 定年及其构造意义. 科学通报, 2004, 49: 592-595

49 Zhang J X, Meng F C, Wan Y S. A cold Early Paleozoic subduction zone in the North Qilian Mountains, NW China: Petrological and U-Pb geochronological constraints. J Metamorph Geol, 2007, 25: 285-304

50 张建新, 许志琴, 陈文, 等. 北祁连中段俯冲-增生杂岩/火山弧的时代探讨. 岩石矿物杂志, 1997, 16: 112-119

51 Wu H Q, Feng Y M, Song S G. Metamorphism and deformation of blueschist belts and their tectonic implications, North Qilian Mountains, China. J Metamorph Geol, 1993, 11: 523-536

52 Liou J G, Wang X M, Colemen R G. Blueschists in major suture zones of China. Tectonics, 1989, 8: 609-619

53 宋述光, 张立飞, Niu Y, 等. 青藏高原北缘早古生代板块构造演化和大陆俯冲. 地质通报, 2004, 23: 918-925

54 吴才来, 徐学义, 高前明, 等. 北祁连早古生代花岗质岩浆作用及构造演化. 岩石学报, 2010, 26: 1027-1044

55 Rapp R P, Watson E B, Miller C F. Partial melting of amphibolite, eclogite and the origin of Archaean trondhjemites and tonalities. Precambrian Res, 1991, 51: 1-25

56 Sen C, Dunn T. Dehydration melting of a basaltic composition amphibolites at 1.5 and 2.0 GPa: Implications for the origin of adakites. Contrib Mineral Petrol, 1994, 117: 394-409

57 Prouteau G, Scaillet B, Pichavant M, et al. Evidence for mantle metasomatism by hydrous silicic melts derived from subducted oceanic crust. Nature, 2001, 410: 197-200

58 Futa K, Stern C R. Sr and Nd isotopic and trace element compositions of Quaternary volcanic centers of the southern Andes. Earth Planet Sci Lett, 1988, 88: 253-263

59 Kay S M, Romas V A, Marquez M. Evidence in Cerro Pampa volcanic rocks for slab-melting prior to ridge-trench collision in southern south America. Geology, 1993, 101: 703-714 
60 Wang Q, McDermott F, Xu J F, et al. Cenozoic K-rich adakitic volcanic rocks in the Hohxil area, northern Tibet: Low crustal melting in an intracontinental setting. Geology, 2005, 33: 465-468

61 Petford N, Atherton M. Na-rich partial melts from newly underplated basaltic crust: The Cordillera Blanca Batholith, Peru. J Petrol, 1996, 37: $1491-1521$

62 Zhang G B, Song S G, Zhang L F, et al. The subducted oceanic crust within continental-type UHP metamorphic belt in the North Qaidam, NW China: Evidence from petrology, geochemistry and geochronology. Lithos, 2008, 104: 99-118

63 Paquette J L, Menot R P, Peucat J J. REE, Sm/Nd and U-Pb zircon study of eclogites from the Alpine External Massifs (Western Alps): Evidence for crustal contamination. Earth Planet Sci Lett, 1989, 96: 181-198

64 Taylor B, Martinez F. Back-arc basin basalt systematics. Earth Planet Sci Lett, 2003, 210: 481-497

65 Pearce J A, Stern R J. The origin of back-arc basin magmas: Trace element and isotope perspectives. In: Christie D M, Fisher C R, Lee S M, et al, eds. Geophysical Monograph. American Geophysical Union, 2006, 166: 63-86

66 夏小洪, 宋述光. 北祁连山肃南九个泉蛇绿岩形成年龄和构造环境. 科学通报, 2010, 55: 1465-1473

67 Zhang L F, Wang Q J, Song S G. Lawsonite blueschist in Northern Qilian, NW China: P-T pseudosections and petrologic implications. J Asian Earth Sci, 2009, 35: 354-366

68 Morris P A. Slab melting as an explanation of Quaternary volcanism and aseismicity in southwest Japan. Geology, 1995, 5: 395-398

69 Peacok S M, Wang K. Seismic consequences of warm versus cool subduction metamorphism: Examples from southwest and northeast Japan. Science, 1999, 286: 937-939

70 Zheng Y F, Xia Q X, Chen R X, et al. Partial melting, fluid supercriticality and element mobility in ultrahigh-pressure metamorphic rocks during continental collision. Earth Sci Rev, 2011, 107: 342-374

71 Zhao Z F, Zheng Y F, Zhang J, et al. Syn-exhumation magmatism during continental collision: Evidence from alkaline intrusives of Triassic age in the Sulu orogen. Chem Geol, 2012, doi: 10.1016/j.chemgeo.2011.11.002

72 Foley S, Tiepolo M, Vannucci R. Growth of early continental crust controlled by melting of amphibolite in subduction zones. Nature, 2002, 417: 837-840

73 Rapp R P, Shimizu N, Norman M D. Growth of early continental crust by partial melting of eclogite. Nature, 2003, 425: 605-609

74 Kelemen P B, Yogodzinski G M, Scholl D W. Along-strike variation in the Aleutian Island Arc: Genesis of high Mg-number andesite and implications for continental crust. In: Eiler J, ed. Inside the Subduction Factory. American Geophysical Union, 2003, 138: 223-276

75 Xiong X L, Adam J, Green T H. Rutile stability and rutile/melt HFSE partitioning during partial melting of hydrous basalt: Implications for TTG genesis. Chem Geol, 2005, 218: 339-359

76 Moyen J F. High Sr/Y and La/Yb ratios: The meaning of the "adakitic signature". Lithos, 2009, 112: 556-574

77 Rapp R P, Shimizu N, Norman M D, et al. Reaction between slab-derived melts and peridotite in the mantle wedge: Experimental constraints at 3.8 GPa. Chem Geol, 1999, 160: 335-356 